\title{
Transformation of humic acid and halogenated byproduct formation in UV-chlorine processes
}

\author{
Tong Li ${ }^{\text {a, c }}$, Yan Jiang ${ }^{\mathrm{d}}$, Xiaoqiang An ${ }^{\mathrm{a}}$, Huijuan Liu ${ }^{\mathrm{b}, \mathrm{c}}$, Chun $\mathrm{Hu}{ }^{\mathrm{b}, \mathrm{c}}$, Jiuhui Qu ${ }^{\mathrm{a}, \mathrm{c}, *}$ \\ ${ }^{a}$ Key Laboratory of Drinking Water Science and Technology, Research Center for Eco-Environmental Sciences, Chinese Academy of Sciences, Beijing 100085, \\ China \\ b State Key Laboratory of Environmental Aquatic Chemistry, Research Center for Eco-Environmental Sciences, Chinese Academy of Sciences, Beijing 100085, \\ China \\ ${ }^{\mathrm{c}}$ University of Chinese Academy of Sciences, Beijing 100049, China \\ d College of Chemistry, Chemical Engineering and Environmental Engineering, Liaoning Shihua University, Liaoning 113001, China
}

\section{A R T I C L E I N F O}

\section{Article history:}

Received 1 March 2016

Received in revised form

20 June 2016

Accepted 24 June 2016

Available online 26 June 2016

\section{Keywords:}

UV-chlorine

Hydroxyl radical

Chlorine radical

Humic acid

Disinfection byproducts

\begin{abstract}
A B S T R A C T
The synergistic effect of ultraviolet light (UV) and chlorine on the structural transformation of Humic Acid (HA) and formation of chloro-disinfection byproducts (DBPs) in water were investigated, with chlorination as a reference. The transformation and mineralization of HA were enhanced upon coexposure to UV and chlorine. Electron spin resonance (ESR) studies revealed that hydroxyl radical $(\cdot \mathrm{OH})$ and chlorine radical $(\cdot \mathrm{Cl})$ were predominant active species in a pH range from 4 to 7 , while ${ }^{\circ} \mathrm{Cl}$ dominated at $\mathrm{pH} 2$ and $\mathrm{pH}$ higher than 7. The impact of different radicals on the transformation of HA was investigated by $\mathrm{UV}_{254}$, fluorescence and TOC measurements. ${ }^{\circ} \mathrm{OH}$ were found to be responsible for the removal of chromophoric groups and mineralization of $\mathrm{HA}$, while $\cdot \mathrm{Cl}$ mainly reacted with $\mathrm{HA}$ and intermediates from HA degradation. Due to the competitive and synergistic reaction of ${ }^{\circ} \mathrm{OH}$ and ${ }^{\circ} \mathrm{Cl}$ with HA, higher removal of HA and lower formation of chloro-DBPs appeared in UV-chlorine than chlorination, thus the combined UV-chlorine processes should be a promising method for water purification.
\end{abstract}

(c) 2016 Published by Elsevier Ltd.

\section{Introduction}

Ultraviolet (UV) irradiation is a promising alternative as a primary disinfectant that does not produce disinfection byproducts (DBPs) (Liberti et al., 2002; Li and Blatchley, 2009; Weng et al., 2012). It is usually used together with chlorine to achieve multiple-barrier disinfection and maintain residual protection. With addition of chlorine before or during UV disinfection, coexposure to both chlorine and UV light could lead to different changes in natural organic matter (NOM) and formation of DBPs. According to previous works, the following processes are involved under different $\mathrm{pH}$ conditions during the photochemical reactions of chlorine in water (Buxton and Subhani, 1971; Oliver and Carey, 1977; Nowell and Hoigne, 1992):

$\mathrm{HOCl} \rightarrow \mathrm{OCl}^{-}+\mathrm{H}^{+} \mathrm{pKa}=7.525^{\circ} \mathrm{C}$

\footnotetext{
* Corresponding author. Key Laboratory of Drinking Water Science and Technology, Research Center for Eco-Environmental Sciences, Chinese Academy of Sciences, Beijing 100085, China.

E-mail address: jhqu@rcees.ac.cn (J. Qu).
}

$$
\begin{aligned}
& \mathrm{HOCl}+h v(\mathrm{UV} \text { photons }) \rightarrow \cdot \mathrm{OH}+\cdot \mathrm{Cl} \\
& \mathrm{OCl}^{-}+h v(\mathrm{UV} \text { photons }) \rightarrow \mathrm{O}^{\cdot-}+\cdot \mathrm{Cl} \\
& \mathrm{O}^{--}+\mathrm{H}_{2} \mathrm{O} \rightarrow \cdot{ }^{-} \mathrm{OH}+\mathrm{OH}^{-} \\
& \cdot \mathrm{Cl}+\mathrm{OH}^{-} \rightarrow \mathrm{ClOH}^{-}
\end{aligned}
$$

Different forms of free chlorine under UV irradiation in aqueous solution would generate different reactive radicals, and induce a series of radical-type chain reactions. NOM is ubiquitous in natural water and acts as the major precursor for DBPs in drinking water (Kim and Yu, 2007; Tian et al., 2013). Upon UV and chlorine coexposure, NOM may be attacked simultaneously by free chlorine species and different radicals (such as $\cdot \mathrm{OH}$ and $\bullet \mathrm{Cl}$ ). Thus, the DBPs formed may greatly differ from those from chlorination alone. However, information on DBPs generation during combined UV and chlorine treatment is scarce, as most studies have focused on sequential exposure to UV and free chlorine/chloramine (Lyon et al., 2012). Some researchers found no significant increase in DBPs in sequential exposure to UV and free chlorine (Zhao et al., 
2011), while other findings indicated that some DBPs such as chloroform (TCM), dichloroacetic acid (DCAA), trichloroacetic acid (TCAA) and cyanogen chloride (DCAN) showed statistically significant enhancements (Liu et al., 2006; Wang et al., 2015b). Above results were predominantly attributed to the impact of UV irradiation on the DBPs precursors, in which NOM was degraded into smaller molecules (Liu et al., 2012a), increasing the reactivity with chlorine. The UV and chlorine co-exposure process involved chlorine atom $(\cdot \mathrm{Cl}), \cdot \mathrm{OH}$ and its conjugate base $\mathrm{O}^{\cdot-}$ with high free radical concentration (Watts and Linden, 2007; Jin et al., 2011; Chan et al., 2012), which is fundamentally different from the reactive species in sequential exposure.

Humic acid (HA), a major component of NOM, is ubiquitous in drinking water. The contamination of HA not only affects the odor, color and taste of water, but also prevents the adsorption of target substances, and forms complexes with heavy metals and micropollutants (Li and Korshin, 2002; Ates et al., 2007). Importantly, in the presence of chlorine radicals with strong oxidizing abilities, HA has been found to be an important precursor for the formation of DBPs (Kim and Yu, 2007; Philippe et al., 2010). Upon UV and chlorine co-exposure, the interactions between HA molecules and radicals further complicate the reactions. However, the transformation of HA and the formation of DBPs have not been verified during co-exposure to UV and chlorine. On the other hand, the role of $\cdot \mathrm{Cl}$ has usually been ignored due to the highly nonselective oxidation of $\cdot \mathrm{OH}$ for the destruction of contaminants. In general, $\cdot \mathrm{Cl}$ is strong but selective (Wang et al., 2015b), and can be quickly scavenged $\left(8.5 \times 10^{9} \mathrm{M}^{-1} \mathrm{~s}^{-1}\right)$ by chloride $\left(\mathrm{Cl}^{-}\right)$in free chlorine solutions to form $\mathrm{Cl}_{2}{ }^{-}$, which however has negligible reactivity with NOM (Nagarajan and Fessenden, 1985; Buxton et al., 2000). The role of $\cdot \mathrm{Cl}$ in forming organic DBPs might therefore depend on its competitive reactivity with NOM compared to chloride. Unfortunately, no reaction rate with NOM has been reported. As a hypothetical example, it is assumed that $\cdot \mathrm{Cl}$ reacts with NOM at the same rate as with benzene $\left(1.8 \times 10^{10} \mathrm{M}^{-1} \mathrm{~s}^{-1}\right)$ (Fang et al., 2014), suggesting that the role of $\cdot \mathrm{Cl}$ in organic DBPs formation would be non-negligible. Therefore, it is of great importance for practical water treatment to better understand the processes of HA degradation by co-exposure to UV irradiation and chlorine.

In this study, the influence of UV irradiation and chlorine on the structural transformation of HA molecules as well as the formation of DBPs were systematically investigated. By investigating the role of different radicals on the removal of HA molecules under different $\mathrm{pH}$ conditions, it was found that $\cdot \mathrm{OH}$ radicals were the dominant reactive species for the mineralization reaction, while chlorine radicals $(\cdot \mathrm{Cl})$ played an important role in the destruction of molecular structures. Due to the efficient removal of HA, unprecedented suppression of the formation of intermediate products was also achieved in the condition of co-exposure. Our research not only provides fundamental understanding on the roles of radicals in the structural transformation of HA in UV-chlorine processes, but also has broad applicability for optimizing water treatment by reducing DBPs formation.

\section{Materials and methods}

\subsection{Materials and reagents}

Solutions were prepared from reagent-grade chemicals and ultrapure water $(18.2 \mathrm{M} \Omega / \mathrm{cm})$ supplied by a NANO pure system (Milli-Q). Sodium hypochlorite $(\mathrm{NaOCl})$ solution (about $5 \%$ available chlorine), sodium hydroxide $(\mathrm{NaOH})$, potassium phosphate $\left(\mathrm{KH}_{2} \mathrm{PO}_{4}\right)$, disodium hydrogen phosphate $\left(\mathrm{Na}_{2} \mathrm{HPO}_{4}\right)$, and sodium thiosulfate $\left(\mathrm{Na}_{2} \mathrm{~S}_{2} \mathrm{O}_{3}\right)$ were at analytical grade or better. $\mathrm{N}, \mathrm{N}$ Diethyl-p-phenylenediamine sulfate (DPD) was purchased from
Sinopharm Chemical Reagent Co., Ltd. (Shanghai, China). HA obtained from Sigma Aldrich (St. Louis, MO, USA) was dissolved in ultrapure water and filtered through an ultrafiltration membrane (Millipore $10,000 \mathrm{Da}$ ) to prepare a stock NOM solution. Standards for DBPs analysis: TCM and halogenated volatiles as a mixture of DBPs including DCAN, trichloroacetonitrile (TCAN), chloral hydrate $(\mathrm{CH})$, chloropicrin (CP), 1,1-dichloropropanone (DCP) and 1,1,1trichloro-2-propanone (TCP) were purchased from AccuStandard (USA). Two species of haloacetic acids (HAAs), DCAA and TCAA, were purchased from Biomart Ltd. (China).

\subsection{UV reactor}

A UV reactor consisting of a stainless steel tube (i.d. $=3.2 \mathrm{~cm})$ with a volume of $100 \mathrm{~mL}$ was used. A LP-Hg UV lamp (TUV 16W T5 4P-SE, Philips, Netherlands) with quartz sleeve (i.d. $=2.2 \mathrm{~cm}$ ) was fixed in the center of the reactor. The UV intensity was measured using an ultraviolet radiometer at the value of $3.06 \mathrm{~mW} / \mathrm{cm}^{2}$.

\subsection{Experimental procedures}

Chlorination experiments were carried out in a $100 \mathrm{~mL}$ batch reactor equipped with a stir bar to ensure homogeneous reaction, which was controlled at $25 \pm 1{ }^{\circ} \mathrm{C}$. Experiments were initiated by adding calculated aliquots of concentrated chlorine solution to the reactor containing HA (dissolved organic carbon DOC $=3.5 \mathrm{mg} / \mathrm{L}$ ), with chlorine dosage of $20 \mathrm{mg} / \mathrm{L}$ in all cases. Solution $\mathrm{pH}$ was adjusted with small volumes of $0.01,0.1$, or $1 \mathrm{M} \mathrm{H}_{2} \mathrm{SO}_{4}$ and $\mathrm{NaOH}$

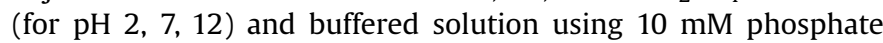
solutions (for $\mathrm{pH} \mathrm{6-8).}$

UV irradiation alone was carried out without chlorine in UV reactor. For the co-exposure of UV and chlorine, it was carried out in the presence of chlorine with UV irradiation. Chlorine solution was added into a $100 \mathrm{~mL}$ HA solution with the initial concentration of DOC at $3.5 \mathrm{mg} / \mathrm{L}$ in all cases. Then, solution $\mathrm{pH}$ was adjusted under vigorous stirring. After $30 \mathrm{~s}$, the solution was rapidly poured into the UV reactor.

At given time intervals during all processes, $2 \mathrm{~mL}$ of solution was rapidly transferred into an plastic centrifuge tube containing $10 \mathrm{mM} \mathrm{Na} 2 \mathrm{~S}_{2} \mathrm{O}_{3}$ (molar ratio of $\mathrm{Na}_{2} \mathrm{~S}_{2} \mathrm{O}_{3} / \mathrm{HOCl}=1$ ) to quench the reaction and stored for analysis of the concentration of HA using UV/Vis absorbance analysis, fluorescence spectroscopy and gel filtration chromatography (GPC). Additionally, $1 \mathrm{~mL}$ of solution was taken for analysis of the concentration of chlorine residual. After the reaction, DOC of the HA solution was measured using TOC- $\mathrm{V}_{\mathrm{CPH}}$ in all cases. At least two replications of each experiment were carried out.

\subsection{Analytical methods}

A total organic carbon analyzer TOC- $\mathrm{V}_{\mathrm{CPH}}$ (Shimadzu Co., Japan) was used to measure DOC. The concentration of residual chlorine was standardized by the $N, N$-Diethyl-p-phenylenediamine spectrophotometry method (DPD). The UV/Vis absorbance was measured in a U-3010 spectrophotometer (Hitachi HighTechnologies Co., Japan) in the range from $200 \mathrm{~nm}$ to $800 \mathrm{~nm}$. The specific UV absorbance at $254 \mathrm{~nm}$ was used to evaluate the degradation of HA. Fluorescence spectroscopic (FS) analysis was carried out using a fluorescence spectrometer (F-4600, Hitachi High-Technologies Co., Japan) in steady state mode with L-geometry. Fluorescence spectra were recorded with the excitation wavelengths in the range of $200-400 \mathrm{~nm}$ and the emission wavelengths in the range of 290-550 nm. GPC used a PL-GPC 50 system (Agilent Co., USA) equipped with a photodiode array UV/Vis detector (SPD-M10A). A TSK-GEL column (G3000PWxl, 
$7.8 \times 300 \mathrm{~mm}$, Tosoh Bioscience) was calibrated with polystyrene sulfonate standards (American Polymer Standard). The GPC mobile phase was a $0.004 \mathrm{M}$ phosphate buffer adjusted to an ionic strength of $0.1 \mathrm{M} \mathrm{NaCl}$ at $\mathrm{pH} 6.8$. The flow rate was $0.6 \mathrm{~mL} / \mathrm{min}$, the sample injection volume was $50 \mu \mathrm{L}$, and the detector wavelength was set at $254 \mathrm{~nm}$. Electron spin resonance (ESR) spectra were measured using a Bruker Electron Paramagnetic Resonance Spectrometer (ESP 300E). TCM, CH, CP, DCP, TCP, DCAN and TCAN were extracted by MTBE and analyzed by EPA method 551.1. The DBPs were measured by gas chromatography with an electron capture detector (GC/ECD) (Agilent, USA) with an HP-5 fused silica capillary column $(30 \mathrm{~m} \times 0.25 \mathrm{~mm} \times 0.25 \mu \mathrm{m})$. Two species of haloacetic acids (DCAA and TCAA) were extracted by MTBE followed by methylation using acidic methanol following EPA method 552.3.

\section{Results and discussion}

\subsection{Degradation of HA by UV-chlorine processes}

The synergetic effect of UV irradiation and chlorine on the removal of HA was investigated. Fig. 1 shows the changes of absorbance of HA at $254 \mathrm{~nm}$ as a function of time, during chlorination, UV irradiation and UV-chlorine processes at $\mathrm{pH}$ 7.0, respectively. Less than $5 \%$ of $\mathrm{HA}$ was degraded within $5 \mathrm{~min}$ in either chlorination or UV irradiation. Even with the duration of chlorination prolonged to $36 \mathrm{~h}$, only $35 \%$ reduction of the $\mathrm{UV}_{254}$ was achieved. By contrast, in the UV-chlorine processes, about $86.5 \%$ of the $U_{254}$ was reduced and $57 \%$ of TOC was removed within $5 \mathrm{~min}$. The results are attributed to the higher radical concentrations in the co-exposure processes, which contributed to the destruction of HA.

Correspondingly, the concentration of chlorine and the $\mathrm{pH}$ values of the solution were determined. As shown in Fig. 2a, only $16.5 \%$ of chlorine was consumed within $5 \mathrm{~min}$ in chlorination alone, and only $49.9 \%$ of chlorine disappeared after 36 h. By contrast, in UV-chlorine, more than $98 \%$ of chlorine was consumed at $5 \mathrm{~min}$ without HA. Moreover, the chlorine almost completely disappeared at $2 \mathrm{~min}$ in the presence of HA. Similarly, no significant changes in solution $\mathrm{pH}$ were detected within $5 \mathrm{~min}$, and a 0.5 decrease in $\mathrm{pH}$ was observed after $36 \mathrm{~h}$ in chlorination, indicating that the free chlorine mainly existed in the form of $\mathrm{HOCl}$ throughout the reaction, and very little HA was degraded into organic acid (Fig. 2b). In contrast, in the UV-chlorine processes, a quickly decreased in

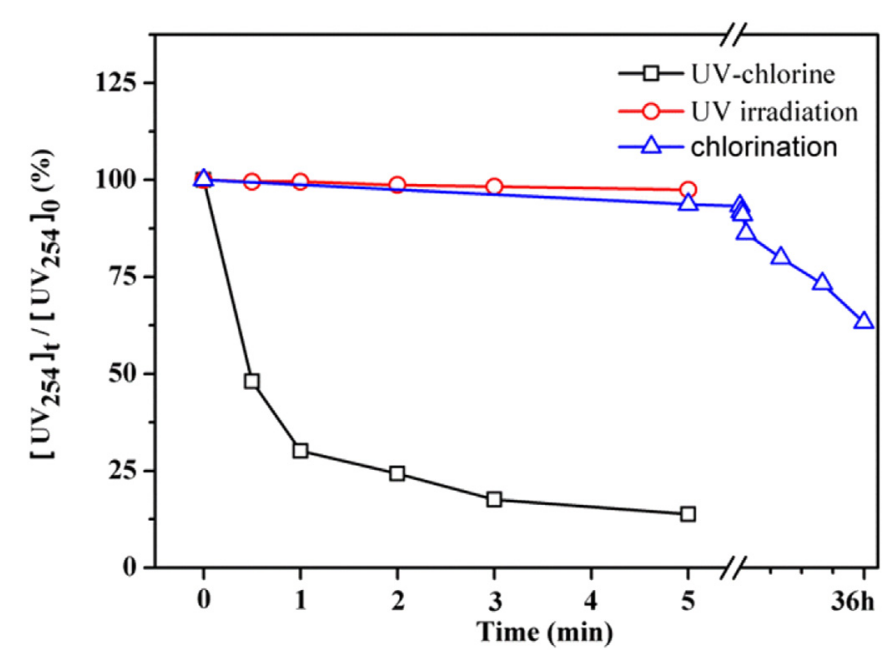

Fig. 1. Degradation of HA as a function of time by chlorination, UV irradiation and UVchlorine processes, respectively (initial $\mathrm{pH}=7$ without buffer solution, $\mathrm{DOC}=3.5 \mathrm{mg}$ / $\mathrm{L}$, chlorine dosage $=20 \mathrm{mg} / \mathrm{L}$ ).
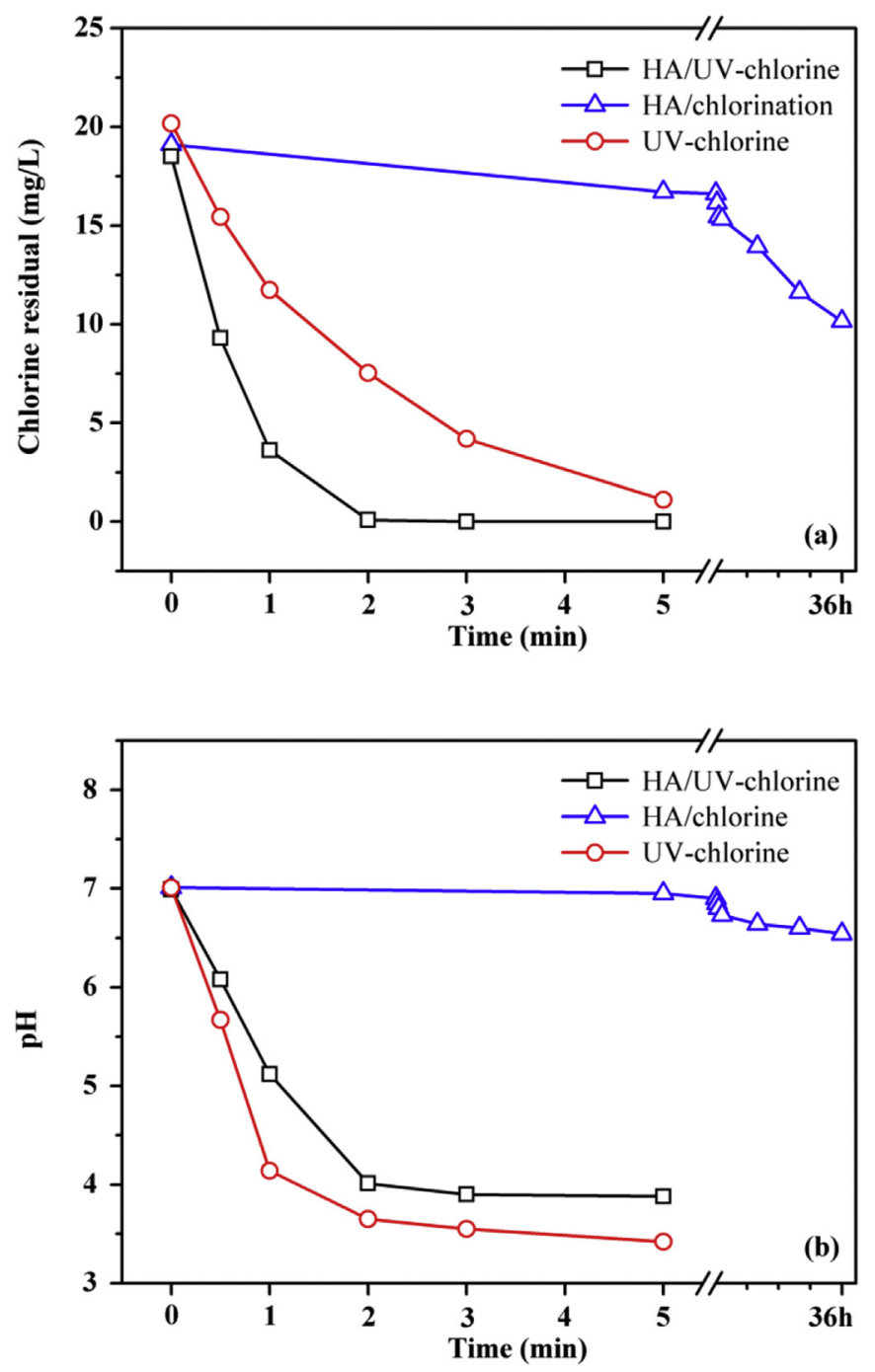

Fig. 2. Change in concentration of (a) chlorine residual and (b) pH as a function of time in UV-chlorine processes without HA, and chlorination and UV-chlorine with HA (DOC $=3.5 \mathrm{mg} / \mathrm{L}$, initial $\mathrm{pH}=7$ without phosphate buffer and chlorine dosage $=20 \mathrm{mg} / \mathrm{L})$.

solution $\mathrm{pH}$ was observed with the increase of reaction time. Compared with chlorine consumption, $\mathrm{pH}$ decreased in solution with HA less than that without HA. Under the usual conditions of photolysis, $\mathrm{HCl}$ is generated from the reaction of $\cdot \mathrm{Cl}$ with $\mathrm{H}_{2} \mathrm{O}$ or $\mathrm{HOCl}$ (Zehavi and Rabani, 1972), which is consistent with the observation that the solution $\mathrm{pH}$ rapidly decreased to 3.43 (Fig. 2b) without HA. In the presence of HA, the consumption rate of chlorine increased, while the decrease rate of $\mathrm{pH}$ slowed down, indicate that the reaction of chlorine radicals with HA occurred by $\mathrm{H}-$ abstraction from the $\mathrm{C}-\mathrm{H}$ bond. As a result, chlorine radicals can easily attack the electron-donating groups, like the unsaturated $\mathrm{C}=$ C bonds (Wang et al., 2012). The possibility for the formation of $\mathrm{C}-\mathrm{Cl}$ bonds undoubtedly suppresses the impact of $\mathrm{HCl}$ molecules on the solution $\mathrm{pH}$.

\subsection{Transformation of $H A$ in $U V$-chlorine with different initial $p H$}

The effects of $\mathrm{pH}$ and chlorine dosage on the mineralization of HA during UV-chlorine processes were evaluated. As shown in Fig. S1, at each given chlorine dosage, the TOC removal rates at $\mathrm{pH} 7$ was much higher than those at $\mathrm{pH} 2$ and $\mathrm{pH} 12$, in which similar 
TOC removal appeared. Moreover, with chlorine dosage increasing from $5 \mathrm{mg} / \mathrm{L}$ to $25 \mathrm{mg} / \mathrm{L}$, the TOC removal was only increased by $10.7 \%$ at initial $\mathrm{pH}$ of 2 and 12, while greatly increased by about $50.11 \%$ at $\mathrm{pH}$ 7. The results indicate that free chlorine is more effectively used for HA mineralization at $\mathrm{pH} 7$ than 2 and 12, which can be possibly ascribed to the photolysis of chlorine at different $\mathrm{pH}$ values.

The form of chlorine existing at different $\mathrm{pH}$ values was studied by calculating the distribution of $\mathrm{Cl}_{2}, \mathrm{HOCl}$ and $\mathrm{OCl}^{-}$in aqueous solution. The proportion of $\mathrm{Cl}_{2}, \mathrm{HOCl}$ and $\mathrm{OCl}^{-}$is not constant under different $\mathrm{pH}$. Since the formation of chlorine depends on the $\mathrm{pH}$ of solution, different reactive species were produced under different $\mathrm{pH}$ conditions with UV-irradiated chlorine, which has been reported in the literature just as equations (2) and (3) (Buxton and Subhani, 1971; Oliver and Carey, 1977; Nowell and Hoigne, 1992). As shown in Fig. S2, the predominant species of chlorine is different at different $\mathrm{pH}$ values. For $\mathrm{pH}$ higher than $7.5, \mathrm{OCl}^{-}$is the main species, while $\mathrm{Cl}_{2}$ is the main species for $\mathrm{pH}$ lower than 2 . In the $\mathrm{pH}$ range from 3 to 7 , the predominant species is $\mathrm{HOCl}$. Therefore, different radicals would be generated upon addition of UV irradiation, resulting in different oxidation abilities.

To ascertain this conjecture, the ESR spin-trap technique (with
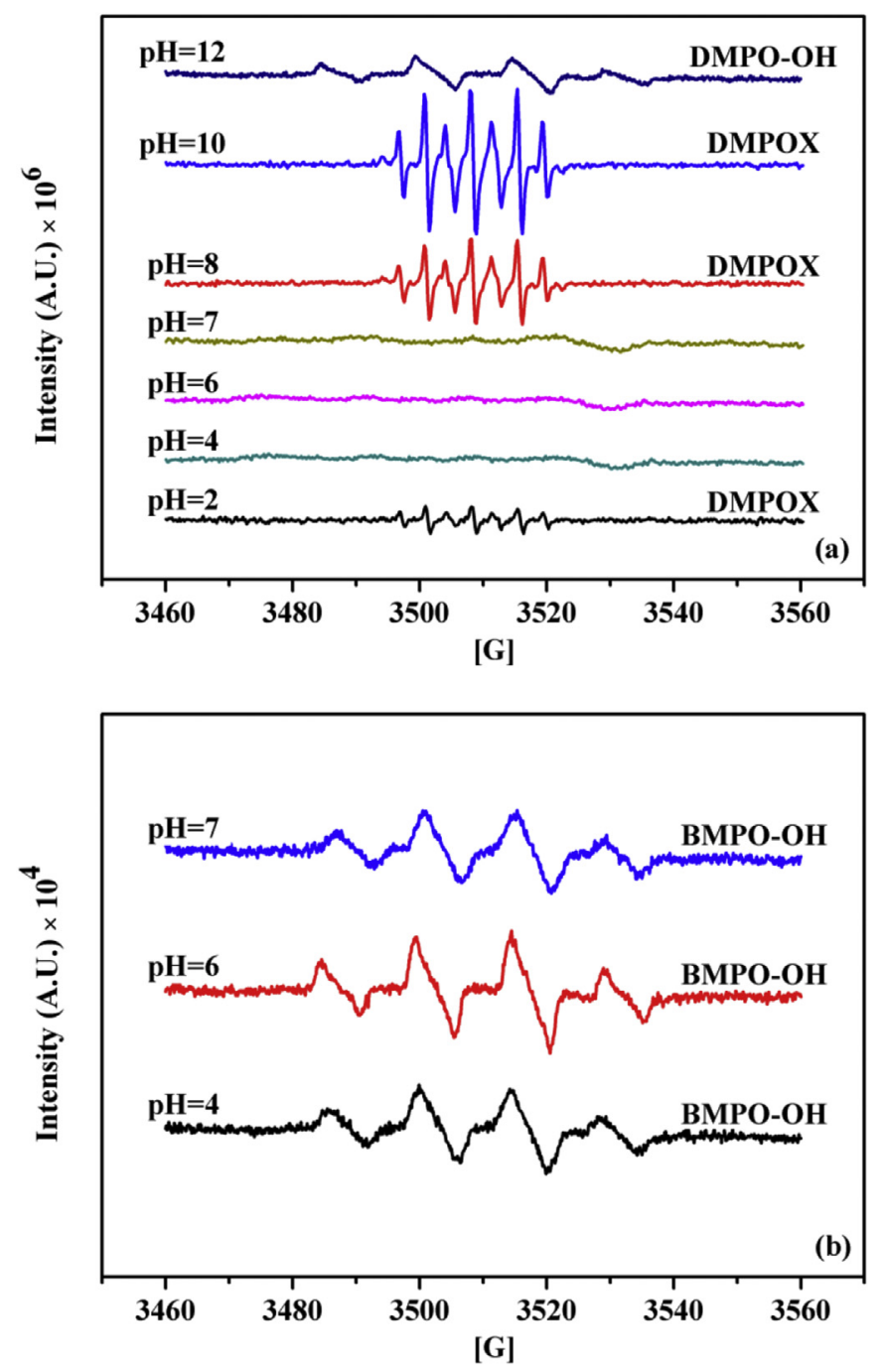

Fig. 3. ESR spectra with (a) DMPO and (b) BMPO observed from photolysis of pure chlorine in absence of HA at different $\mathrm{pH}$ values. (chlorine dosage $=50 \mathrm{mg} / \mathrm{L}$ and the concentration of DMPO and BMPO $=10 \mathrm{mg} / \mathrm{mL}$ ).
DMPO and BMPO) was employed to detect the nature of the reactive oxygen species generated in different reactions (Fig. 3). Typical BMPO- $\cdot \mathrm{OH}$ signals were detected in the range of $\mathrm{pH} 4-7$, while there was no signal with DMPO trapping. However, seven-line ESR spectra were obtained under both acidic $(\mathrm{pH}=2)$ and alkaline conditions ( $\mathrm{pH}=8-10$ ) with DMPO.

Previous studies have demonstrated that the seven-line ESR spectra corresponds to DMPOX, an oxidized derivative formed by the oxidation of DMPO by other radicals (Hill and Thornalley, 1982). According to equations (1)-(4), both $\cdot \mathrm{OH}$ and $\cdot \mathrm{Cl}$ are predominant in the $\mathrm{pH}$ range of $4-7$. Since DMPO is readily oxidizable, it is reasonable to believe that this ESR signal should be attributed to the oxidizing capacity of $\cdot \mathrm{Cl}$ and $\cdot \mathrm{OH}$ during the UV-chlorine processes. DMPO is very possibly oxidized into other non-radical products by both $\cdot \mathrm{OH}$ and $\cdot \mathrm{Cl}$. At $\mathrm{pH}$ higher than 7 and at $\mathrm{pH} 2$, - $\mathrm{Cl}$ is predominant, so the stable DMPOX appears. However, DMPO$\cdot \mathrm{OH}$ signals are observed at $\mathrm{pH} 12$, since under this condition ${ }^{\circ} \mathrm{Cl}$ can react with $\mathrm{OH}^{-}$producing $\mathrm{ClOH}^{-}$and $\mathrm{O}^{\cdot-}$ with $\mathrm{H}_{2} \mathrm{O}$ producing $\cdot \mathrm{OH}$ according to equation (5). These results also verify that DMPOX is derived from the oxidation of DMPO by $\cdot \mathrm{Cl}$, indicating the formation of $\cdot \mathrm{Cl}$ at different $\mathrm{pH}$ values. Thus the main reactive species are $\cdot \mathrm{OH}$ radicals at $\mathrm{pH} 7$, while $\cdot \mathrm{Cl}$ radicals, which have different reaction pathways with $\mathrm{HA}$, are predominant at $\mathrm{pH} 2$ and $\mathrm{pH}$ higher than 7. As a selective oxidant, the presence of $\cdot \mathrm{Cl}$ leads to lower mineralization of contaminants (Fang et al., 2014). As a result, there is higher TOC removal at $\mathrm{pH} 7$ than at $\mathrm{pH} 2$ or 12 .

The structural transformation of HA molecules during the UVchlorine processes was studied by fluorescence measurements. Fig. S3 shows the EEM contour plots for HA before and after reaction at different $\mathrm{pH}$ values. Before reaction, the HA exhibits weaker fluorescence emission at $\mathrm{pH} 2$, and stronger emission at $\mathrm{pH} 7$ and 12 , indicating that solution $\mathrm{pH}$ has an effect on the structure of HA. As humic acid molecules curl up under acidic conditions, the decreased exposure of chromogenic groups should result in relatively low fluorescence intensity (Rodriguez et al., 2014). Furthermore, after co-exposure to UV irradiation and chlorine, the shift of the emission peak and significantly suppressed fluorescence emission at all $\mathrm{pH}$ values indicate that structural transformation of HA molecules occurred due to the efficient removal of chromophoric groups by reactive radicals. More significant removal of chromophoric groups is observed in $\mathrm{pH} 7$, which agrees well with the TOC removal results. This indicates that $\cdot \mathrm{OH}$ radicals play an important role in destroying the conjugated structure of the chromophoric groups. At $\mathrm{pH} 2$ and $\mathrm{pH}$ 12, the lower removal of chromophoric groups observed indicates that the reactivity of $\cdot \mathrm{Cl}$ with $\mathrm{HA}$ is lower due to the formation of $\mathrm{Cl}_{2}{ }^{-}$.

The change of molecular weight during the structural transformation of HA was subsequently investigated by GPC. Fig. S4 shows the molecular weight distribution of HA before and after co-exposure to UV and chlorine at different $\mathrm{pH}$. It is clearly seen that the molecular size of HA is strongly dependent on the $\mathrm{pH}$. In the acidic condition $(\mathrm{pH}=2)$, HA predominantly consisted of low molecular-weight organic matter with low response. Along with the increase of $\mathrm{pH}$ values, both the molecular size and the signal intensity increased. These results can be ascribed to the structural conversion of the HA macromolecule, generally from a coil type in an acidic environment into a linear structure in alkaline solution, where the size of HA becomes larger, due to the increased exposure of $\pi$-electrons in the aromatic rings (Rodriguez et al., 2014). This is presented in the phenomenon that with the same molecular weight, the size and volume of HA increases in alkaline solution, therefore the measurements of GPC is greater than the real value (the initial molecular weight of $\mathrm{HA}=10,000 \mathrm{Da}$ ).

Co-exposure by UV irradiation and chlorine also influences the molecular size distribution of HA. In particular, the peak area and 
height at pH 7 are significantly reduced after the exposure, which indicates the decomposition of HA into fragments with smaller molecular weights. In contrast, the change of molecular size in the acidic solution is negligible, which is in accordance with the poor removal performance of $\mathrm{HA}$. At $\mathrm{pH} \mathrm{12,} \mathrm{the} \mathrm{molecular} \mathrm{size} \mathrm{was}$ distributed over a wide range from 780 to $135,570 \mathrm{Da}$. The results confirm that $\cdot \mathrm{OH}$ radicals are more active than ${ }^{\circ} \mathrm{Cl}$ for reaction with $\mathrm{HA}$, leading to higher TOC removal at $\mathrm{pH} 7$.

\subsection{Formation of DBPs during UV-chlorine processes}

The formation of DBPs during UV-chlorine processes is an interesting and technically important issue, as the co-exposure treatment exhibits obvious impact on the structural
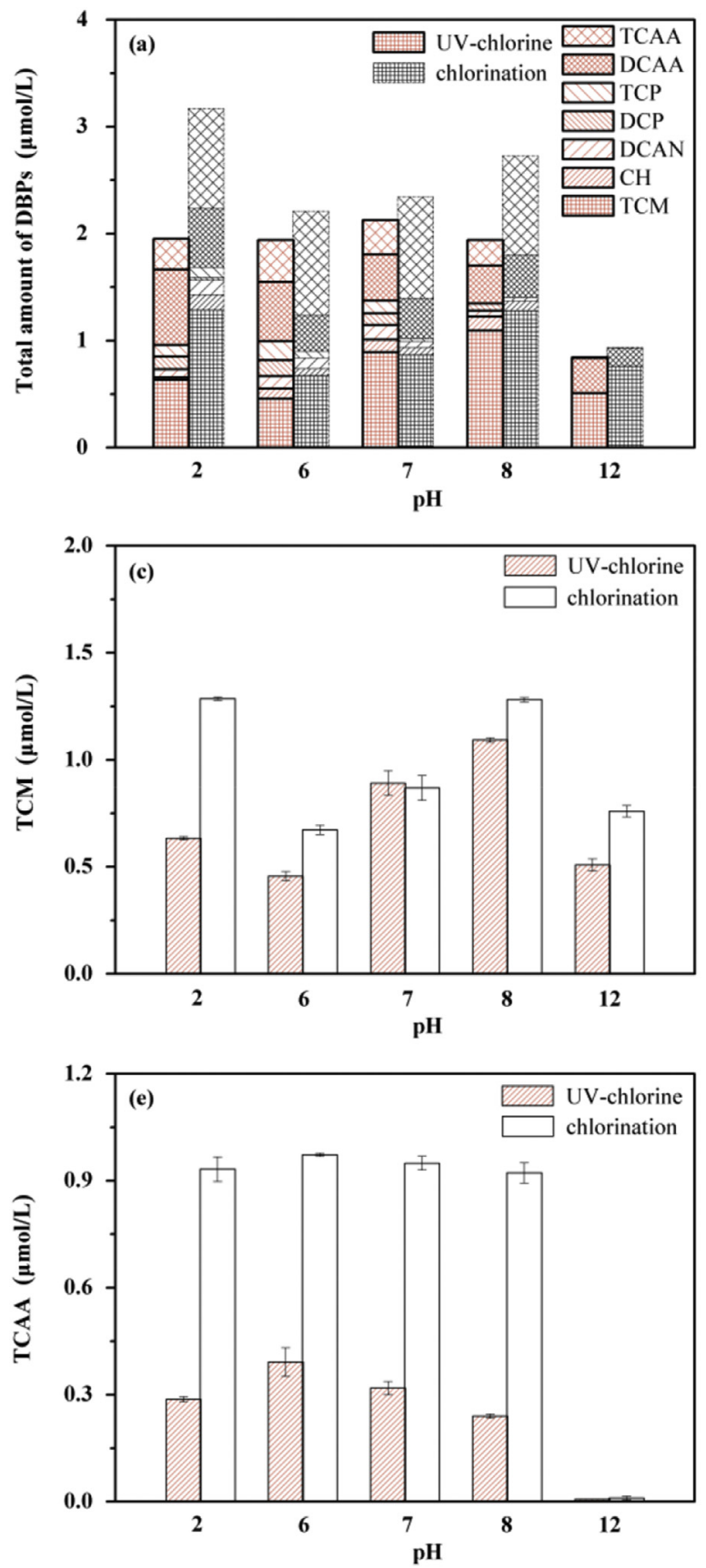

transformation of HA, the dominant precursor for the formation of DBPs (Kim and Yu, 2005). Therefore, the types and quantities of DBPs formed during the degradation of HA were determined at different $\mathrm{pH}$ values in both UV-chlorine and chlorination processes (Fig. 4a). Compared with chlorination alone for $50 \%$ chlorine consumption, lower concentrations of oxidation intermediates occurred in UV-chlorine processes for $100 \%$ chlorine consumption. In addition, the low amount of DBPs is mainly due to the weak oxidizing ability of $\mathrm{OCl}^{-}$, which could not destroy the precursors for formation of DBPs, such as phenyl structures. Therefore, there is an obvious distinction between the oxidation processes in the two systems. In chlorination, TCM, DCAA and TCAA are found to be the dominant intermediates, while TCM, DCAA, TCP and DCP are the primary components of DBPs under co-exposure.
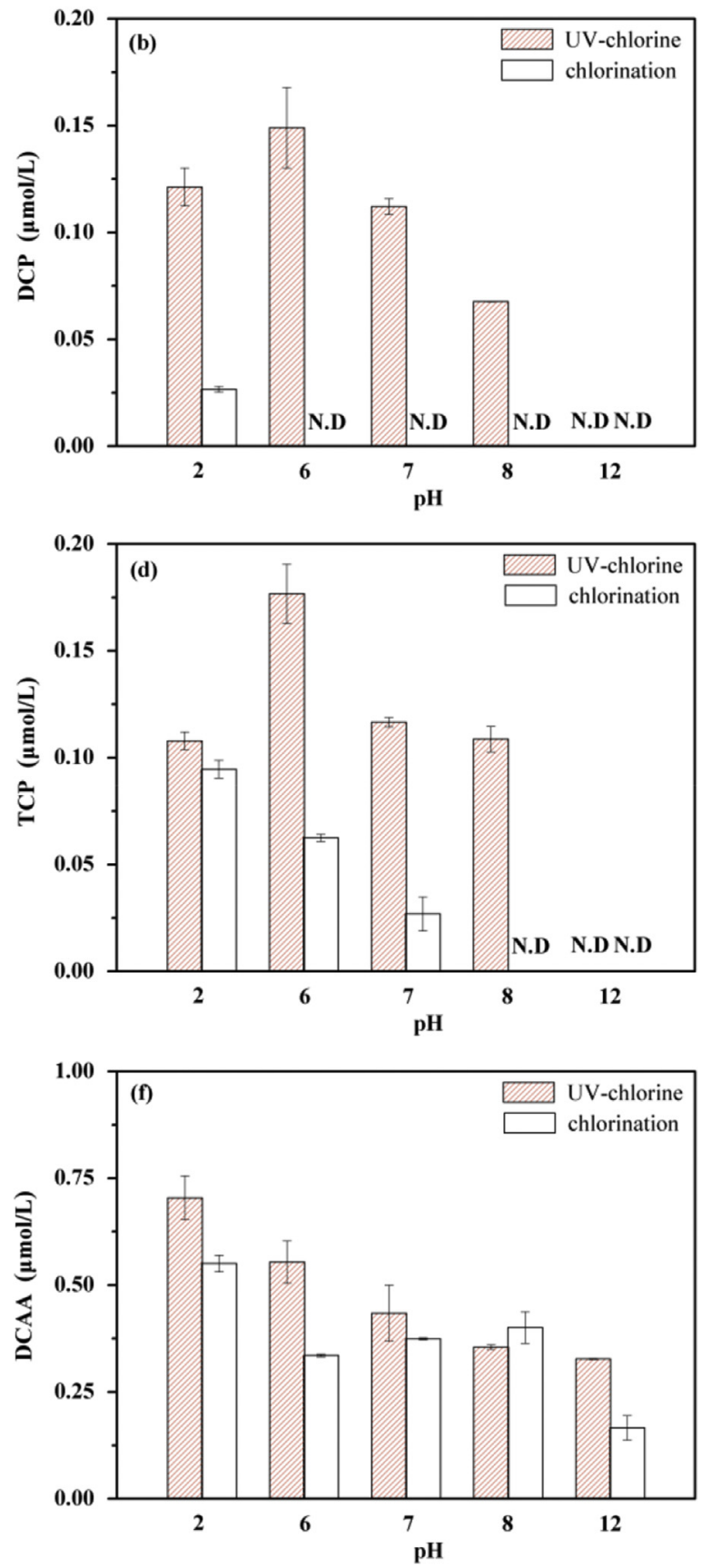

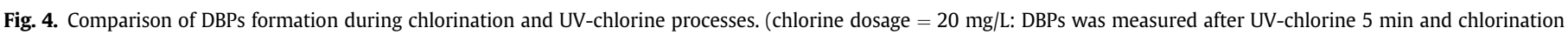
36 h). (a) the total of DBPs including TCM, CH, DCAN, DCP, TCP, DCAA and TCAA. The formation of (b) DCP, (c) TCM, (d) TCP (e) TCAA and (f) DCAA. N.D: undetectable. 
To gain a deeper understanding of the typical DBPs intermediates, the formation process of each component was analyzed. As shown in Fig. 4c, TCM with a concentration of $1.28 \mu \mathrm{mol} / \mathrm{L}$ is formed at $\mathrm{pH} 2$ in chlorination, while $0.63 \mu \mathrm{mol} / \mathrm{L}$ is produced in UV-chlorine due to the reaction of $\cdot \mathrm{Cl}$ with HA molecules (Figs. S3 and S4). At pH 6, the amount of TCM is significantly decreased, which is possibly due to the presence of free chlorine in the form of $\mathrm{HOCl}$ and higher amounts of $\bullet \mathrm{OH}$. Then, TCM increases to the same amount as that at $\mathrm{pH} 2$ and $\mathrm{pH} 8$, due to the common reactive species ${ }^{-} \mathrm{Cl}$ in the two conditions. In the UV-chlorine processes, the TCM formation is lower than in chlorination at different $\mathrm{pH}$. The maximum amount of TCM appears at $\mathrm{pH} 8$, while the minimum amount is at $\mathrm{pH}$ 6. The ESR analysis verifies that the highest amount of $\cdot \mathrm{OH}$ is produced at $\mathrm{pH} 6$, while the main reactive species are $\cdot \mathrm{Cl}$ radicals at $\mathrm{pH}$ 8. These results indicate that TCM is formed mainly from the reaction of $\cdot \mathrm{Cl}$ with $\mathrm{HA}$. In the UV-chlorine processes, the formation of more $\cdot \mathrm{OH}$ inhibits the incorporation of chlorine into HA due to the non-selectivity of $\cdot \mathrm{OH}$ oxidation, leading to lower TCM formation. This indicates that $\cdot \mathrm{OH}$ radicals are prone to attack precursors such as those with unsaturated $\mathrm{C}-\mathrm{C}$ bonds, conjugated double bonds and aromatic groups, because phenolic hydroxyl and conjugated double bonds are primarily responsible for TCM and TCAA formation according to previous works (Li et al., 2011; Tian et al., 2013).

The formation of DCP and TCP is much higher under coexposure than for chlorination alone (Fig. $4 \mathrm{~b}$ and d). In particular, in chlorination, DCP only appeared at $\mathrm{pH} 2$, and neither DCP nor TCP were detected at $\mathrm{pH} 8$ and 12 . It is well known that $\cdot \mathrm{OH}$ can readily react with organic compounds by $\mathrm{H}$-abstraction from the C $-\mathrm{H}$ bond (Barton and Howlett, 1949; von Sonntag, 2007), producing lower molecular weight molecules such as ketones, aldehydes, and carboxylic acids and even lead to mineralization. It is worth mentioning that DCP is hardly formed during chlorination alone. However, DCP is found to be the major product in the presence of UV and chlorine at $\mathrm{pH} 6$ or 7. Thus, the apparent formation of DCP and TCP upon UV-chlorine treatment is possibly due to the reaction of $\cdot \mathrm{Cl}$ with these small intermediates.

The total amount of HAAs is much lower in the UV-chlorine coexposure treatment than for chlorination, as shown in Fig. 4e and 4f. However, a higher amount of DCAA was formed in the former condition, while more TCAA was formed in the latter. Some studies have shown that the DCAA precursor is mainly compounds with carboxyl and alcohol hydroxyl groups (Li et al., 2011), while the TCAA precursor is mainly those with phenolic hydroxyl and conjugated double bonds. Based on the transformation of HA in UVchlorine and chlorine, carboxyl and alcohol hydroxyl intermediates are predominant, leading to higher DCAA formation for UV-chlorine treatment, while phenolic hydroxyl and conjugated double bonds are dominant in intermediates, leading to higher TCAA formation in chlorination.

Furthermore, the effects of $\mathrm{Ca}^{2+}$ and $\mathrm{Mg}^{2+}$ were also examined, and it was found that both metal ions did not show great influence on the degradation of HA (Fig. S5a), but inhibit the formation of $\mathrm{CH}$ (Fig. S5b) which contributed to the complex of $\mathrm{Ca}^{2+}$ and $\mathrm{Mg}^{2+}$ with carboxyl groups. $\mathrm{Ca}^{2+}$ and $\mathrm{Mg}^{2+}$ could bind with $\mathrm{HA}$ and forming $\mathrm{HA}-\mathrm{Ca}^{2+}$ and HA-Mg${ }^{2+}$ complexes (Wang et al., 2015a). And the complexing step was a factor for reduction of $\mathrm{CH}$, which led to a variation in electron density of active sites on HA (Navalon et al., 2009; Liu et al., 2012b).

\subsection{Kinetic and formation pathway of DBPS}

The kinetics of TCM, DCP, TCP, DCAA and TCAA formation were investigated and the results are shown in Fig. S6. At pH 12, a little of TCM and DCAA were formed within the reaction time, other DBPs

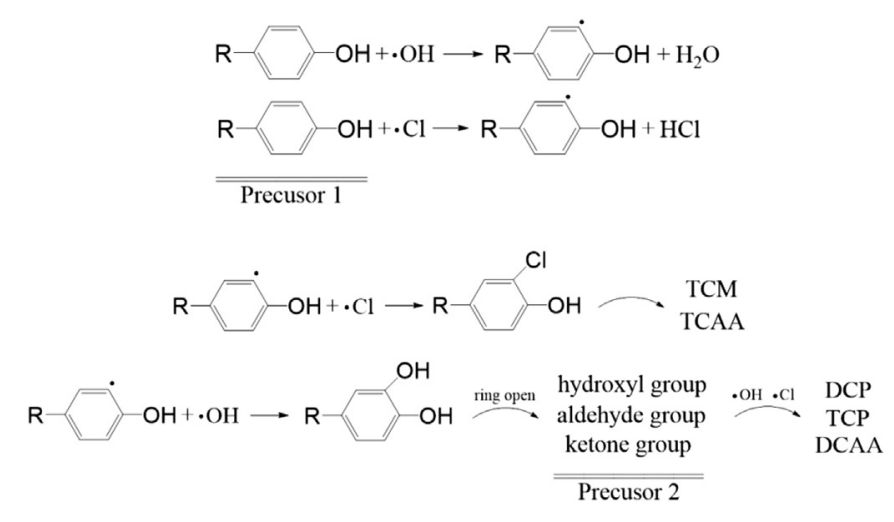

Fig. 5. Formation pathway of the DBPs in UV-chlorine processes.

were hardly produced, which was due to the lower oxidizing ability of $\mathrm{OCl}^{-}$. However, before the chlorine was completely consumed at 3 min, the concentrations of DCP (Fig. S6b), TCP (Fig. S6d) and DCAA (Fig. S6e) significantly increased at the other tested $\mathrm{pH}$, whereas TCAA slightly increased with time increasing, but TCM (Fig. S6a) hardly increased after 0.5 min under the same conditions. Additionally, the generated quantity of TCM under different $\mathrm{pH}$ increased by the order of $\mathrm{pH} 6<\mathrm{pH} 7<\mathrm{pH} 8$, while those of DCP, TCP and DCAA increased by the order of $\mathrm{pH} 8<\mathrm{pH} 7<\mathrm{pH} 6$, respectively. The ESR measurement have verified that the concentration of $\cdot \mathrm{Cl}$ was stable within $\mathrm{pH} 6-8$, while the concentration of -OH increased with the decrease of $\mathrm{pH}$. The results confirmed that $\cdot \mathrm{OH}$ was responsible for the formation of DCP, TCP and DCAA, $\cdot \mathrm{Cl}$ contributed to the formation of TCM. A slight increase of TCAA (Fig. S6c) might result from the further conversion of small molecules substances oxidized by $\cdot \mathrm{Cl}$ and $\cdot \mathrm{OH}$.

According the effect of $\mathrm{pH}$ and the kinetic of DBPs production, the formation pathway of the DBPs in UV-chlorine was proposed in Fig. 5. Firstly, precusor 1 (phenolic hydroxyl and conjugated double bonds) for TCM and TCAA was attacked by $\cdot \mathrm{Cl}$ and $\cdot \mathrm{OH}$ on the $\mathrm{H}-$ abstract rapidly. Further oxidation of precusor 1 resulted in the formation of TCM and TCAA within $0.5 \mathrm{~min}$. Others were oxidized to open the ring and form more hydroxyl, aldehyde and ketone groups by $\cdot \mathrm{OH}$, as precusor 2 was easy to produce DCP, TCP and DCAA.

\section{Conclusions}

This study indicated that synergetic effects between UV irradiation and chlorine treatment could significantly enhance the transformation and mineralization of HA. In the UV-chlorine processes, the main reactive species are $\cdot \mathrm{OH}$ and $\cdot \mathrm{Cl}$ radicals, resulting in more TOC removal and less DBPs formation in the $\mathrm{pH}$ range of 4-7, while at other $\mathrm{pH}$ values, $\cdot \mathrm{Cl}$ radicals are dominant, leading to lower TOC removal and higher DBPs formation. The low amount of chloro-DBPs generated during the UV-chlorine processes can be attributed to the high removal rate of $\mathrm{HA}$, the competitve reactions between $\cdot \mathrm{OH}, \cdot \mathrm{Cl}$ radicals and $\mathrm{HA}$ and degradation of intermediates. Consequently, this study provides important technical and fundamental knowledge for the possible application of UV-chlorine technology in the field of drinking water disinfection.

\section{Acknowledgements}

This work was supported by the National Natural Science Foundation of China (grant No. 51290280). 


\section{Appendix A. Supplementary data}

Supplementary data related to this article can be found at http:// dx.doi.org/10.1016/j.watres.2016.06.051.

\section{References}

Ates, N., Kitis, M., Yetis, U., 2007. Formation of chlorination by-products in waters with low SUVA-correlations with SUVA and differential UV spectroscopy. Water Res. 41 (18), 4139-4148.

Barton, D.H.R., Howlett, K.E., 1949. The kinetics of the dehydrochlorination of substituted hydrocarbons. Part I. Induced Dehydrochlorination. J. Chem. Soc. 148-155.

Buxton, G.V., Bydder, M., Salmon, G.A., Williams, J.E., 2000. The reactivity of chlorine atoms in aqueous solution Part III. The reactions of $\mathrm{Cl}^{\bullet}$ with solutes. Phys. Chem. Chem. Phys. 2, 237-245.

Buxton, G.V., Subhani, M.S., 1971. Radiation-chemistry and photochemistry of oxychlorine ions. Part 1. - Radiolysis of aqueous solutions of hypochlorite and chlorite ions. J. Chem. Soc. 68, 947-957.

Chan, P.Y., Gamal El-Din, M., Bolton, J.R., 2012. A solar-driven UV/Chlorine advanced oxidation process. Water Res. 46 (17), 5672-5682.

Fang, J.Y., Fu, Y., Shang, C., 2014. The roles of reactive species in micropollutant degradation in the UV/free chlorine system. Environ. Sci. Technol. 48 (3), 1859-1868.

Hill, H.A.O., Thornalley, P.J., 1982. The oxidative ring opening of the cyclic nitrone spin trap 5,5-Dimethyl-1-pyrroline-1-oxide (DMPO): free radical involvment. Inorganica Chim. Acta 67, L35-L36.

Jin, J., El-Din, M.G., Bolton, J.R., 2011. Assessment of the UV/chlorine process as an advanced oxidation process. Water Res. 45 (4), 1890-1896.

Kim, H.C., Yu, M.J., 2005. Characterization of natural organic matter in conventional water treatment processes for selection of treatment processes focused on DBPs control. Water Res. 39 (19), 4779-4789.

Kim, H.C., Yu, M.J., 2007. Characterization of aquatic humic substances to DBPs formation in advanced treatment processes for conventionally treated water J. Hazard. Mater. 143 (1-2), 486-493.

Li, A.Z., Zhao, X., Liu, H.J., Qu, J.H., 2011. Characteristic transformation of humic acid during photoelectrocatalysis process and its subsequent disinfection byproduct formation potential. Water Res. 45 (18), 6131-6140.

Li, C.W., Korshin, G.V., 2002. Studies of metal-binding sites in natural organic matter and their role in the generation of disinfection byproducts using lanthanide ion probes. Chemosphere 49, 629-636.

Li, J., Blatchley 3rd, E.R., 2009. UV photodegradation of inorganic chloramines. Environ. Sci. Technol. 43 (1), 60-65.

Liberti, L., Notarnicola, M., Petruzzelli, D., 2002. Advanced treatment for municial wastewater reuse in agriculture. UV disinfection: parasite removal and byproduct formation. Desalination 152 (1-3), 315-324.

Liu, W., Cheung, L.M., Yang, X., Shang, C., 2006. THM, HAA and $\mathrm{CNCl}$ formation from UV irradiation and chlor(am)ination of selected organic waters. Water Res. 40 (10), 2033-2043.
Liu, W., Zhang, Z., Yang, X., Xu, Y., Liang, Y., 2012a. Effects of UV irradiation and UV/ chlorine co-exposure on natural organic matter in water. Sci. Total Environ. 414, $576-584$.

Liu, X., Chen, Z., Wang, L., Shen, J., 2012b. Effects of metal ions on THMs and HAAs formation during tannic acid chlorination. Chem. Eng. J. 211-212, 179-185.

Lyon, B.A., Dotson, A.D., Linden, K.G., Weinberg, H.S., 2012. The effect of inorganic precursors on disinfection byproduct formation during UV-chlorine/chloramine drinking water treatment. Water Res. 46 (15), 4653-4664.

Nagarajan, V., Fessenden, R.W., 1985. Flash photolysis of transient radicals. 1. Xwith $\mathrm{X}=\mathrm{Cl}$, Br, I and $\mathrm{SCN}^{-}$. J. Phys. Chem. 89, 2330-2335.

Navalon, S., Alvaro, M., Garcia, H., 2009. $\mathrm{Ca}^{2+}$ and $\mathrm{Mg}^{2+}$ present in hard waters enhance trihalomethane formation. J. Hazard. Mater. 169 (1-3), 901-906.

Nowell, L.H., Hoigne, J., 1992. Photolysis of aqueous chlorine at sunlight and ultraviolet wavelengths -II.Hydroxyl radical production. Water Res. 26 (5), 599-605.

Oliver, B.G., Carey, J.H., 1977. Photochemical production of chlorinated organics in aqueous solutions containing chlorine. Environ. Sci. Technol. 11 (9), 893-895.

Philippe, K.K., Hans, C., MacAdam, J., Jefferson, B., Hart, J., Parsons, S.A., 2010. Photocatalytic oxidation of natural organic matter surrogates and the impact on trihalomethane formation potential. Chemosphere 81 (11), 1509-1516.

Rodriguez, F.J., Schlenger, P., Garcia-Valverde, M., 2014. A comprehensive structural evaluation of humic substances using several fluorescence techniques before and after ozonation. Part I: structural characterization of humic substances. Sci. Total Environ. 476-477, 718-730.

Tian, C., Liu, R.P., Liu, H.J., Qu, J.H., 2013. Disinfection by-products formation and precursors transformation during chlorination and chloramination of highlypolluted source water: significance of ammonia. Water Res. 47 (15), 5901-5910.

von Sonntag, C., 2007. The basics of oxidants in water treatment. Part A: OH radical reactions. Water Sci. Technol. 55 (12), 19-23.

Wang, L.F., He, D.Q., Chen, W., Yu, H.Q., 2015a. Probing the roles of $\mathrm{Ca}^{2+}$ and $\mathrm{Mg}^{2+}$ in humic acids-induced ultrafiltration membrane fouling using an integrated approach. Water Res. 81, 325-332.

Wang, D., Bolton, J.R., Andrews, S.A., Hofmann, R., 2015b. Formation of disinfection by-products in the ultraviolet/chlorine advanced oxidation process. Sci. Total Environ. 518-519, 49-57.

Wang, D., Bolton, J.R., Hofmann, R., 2012. Medium pressure UV combined with chlorine advanced oxidation for trichloroethylene destruction in a model water. Water Res. 46 (15), 4677-4686.

Watts, M.J., Linden, K.G., 2007. Chlorine photolysis and subsequent $\mathrm{OH}$ radical production during UV treatment of chlorinated water. Water Res. 41 (13), 2871-2878.

Weng, S., Li, J., Blatchley 3rd, E.R., 2012. Effects of UV 254 irradiation on residual chlorine and DBPs in chlorination of model organic-N precursors in swimming pools. Water Res. 46 (8), 2674-2682.

Zehavi, D., Rabani, J., 1972. Oxidation of aqueous bromide ions by hydroxyl radicals. Pulse radiolytic investigation. J. Phys. Chem. 76 (3), 312-319.

Zhao, Q., Shang, C., Zhang, X., Ding, G., Yang, X., 2011. Formation of halogenated organic byproducts during medium-pressure UV and chlorine coexposure of model compounds, NOM and bromide. Water Res. 45 (19), 6545-6554. 